Acta Genet Med Gemellol 42: 295-297 (1993)

(c) by The Mendel Institute, Rome

Received 17 June 1993

Final 23 October 1993

\title{
Latent Menstrual Cycle in Pre-Menarcheal Monozygotic Twins
}

\author{
I. Nakamura', C. Harada', T. Miura² \\ 1 Japan Women's College of Physical Education, Tokyo, and ${ }^{2}$ Teikyo University School of \\ Medicine, Tokyo
}

\begin{abstract}
The distribution of menarcheal interval-length between cotwins in 67 pairs of female identical twins in Tokyo was found to cluster at fairly constant intervals. When delayed in one twin, the menarche occurred in the second twin at intervals of approximately 28 days after that of the earlier twin. This finding suggests the existence of a latent lunar or menstrual cycle in pre-menarcheal girls, evidence for which was detected by recording the menarcheal intervals between $\mathrm{MZ}$ cotwins in days.
\end{abstract}

Key words: Latent menstrual cycle, Pre-menarcheal, Monozygotic female twins

\section{INTRODUCTION}

It is not surprising that a higher rate of menarcheal concordance has been found among monozygotic $(\mathrm{MZ})$ twin girls than that among dizygotic $(\mathrm{DZ})$ twin girls [2,3,4]. Data in these studies, however, were only based on monthly observations: In our study we tried to determine the precise menarcheal interval length in days for each pair of cotwins.

\section{MATERIALS AND METHODS}

218 pairs of twin girls in Tokyo, born between 1968 and 1977 and aged 11-12 were studied during their last year of elementary school. The object of the study was to determine the precise date of the menarche in these pairs of female twins. At the time of the study, the menarche had been experienced by one or both cotwins in 127 (110 MZ and $17 \mathrm{DZ}$ ) pairs. In $15 \mathrm{MZ}$ and $6 \mathrm{DZ}$ pairs, one cotwin had not experienced the menarche by this time. Data on the month in which the menarche occurred only was obtained from 
$28 \mathrm{MZ}$ and $5 \mathrm{DZ}$ pairs. The precise date of the menarche was obtained from $67 \mathrm{MZ}$ and $6 \mathrm{DZ}$ pairs.

\section{RESULTS}

Within the $67 \mathrm{MZ}$ pairs from whom precise menarcheal dates were collected, the mean length of the menarcheal interval between cotwins was 96.9 days, and the median length 79 days. The corresponding figures for the $6 \mathrm{DZ}$ pairs from whom precise menarcheal dates were collected were 277 days and 199 days respectively. These values are similar to those previously reported $[2,3,4]$. Within the $67 \mathrm{MZ}$ pairs, when the menarche was delayed in one twin, it most frequently occurred within 0-6 days of that of her cotwin (0-5 days in the case of 10 twin pairs). Measured in days, the menearcheal intervals clustered in several groups, with peaks around day $3,28,54,83,113,135$ and 167, in 56 of the pairs (see Figure). A further 11 pairs had much longer menarcheal intervals (between 183 and 490 days), but the series of lags between cotwins in all the $67 \mathrm{MZ}$ pairs measured in days approximates to the arithmetic progression $0,28,56,84,112,140,168 \ldots$

\section{DISCUSSION}

It is natural that the menarches of $\mathrm{MZ}$ cotwins should show greater concordance than those of DZ twin girls. Among the $67 \mathrm{MZ}$ twin pairs, 10 pairs showed a high degree of concordance in their menarches, with one twin's menarche occuring within 0-5 days of the other's. In the remaining $57 \mathrm{MZ}$ twin pairs, the menarcheal interval length did not decrease gradually, but was distributed cyclically (see Figure).

This distribution of menarcheal interval length between cotwins in the 67 pairs of $\mathrm{MZ}$ twin girls from whom the precise date of the menarche was obtained, might lead to the following hypothesis: in female $M Z$ twin pairs, where cotwins may have the same congenital 'maturation clock', and have grown up in identical conditions, the physiological cycles of both girls are synchronized and their menarches may coincide. As identical

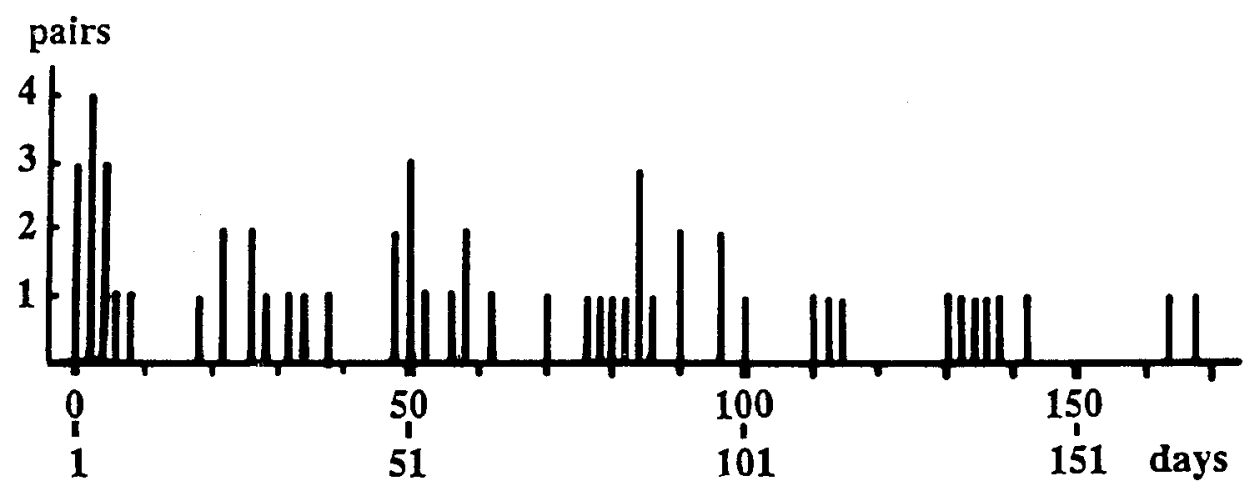

Figure. Distribution of the intervals of menarcheal onset among $M Z$ twin girls in each two-day period after the earlier onset in one cotwin. 
twin sisters have the same 'maturation clock', when the menarche in one cotwin is delayed for some reason, it will only occur after an interval approximating to a certain number of 28-day cycles.

A cyclical disturbance occuring at average intervals of 21-34 days has also been reported in pre-menarcheal diabetic girls [1]. It has been suggested that this is caused by cyclical hormonal disturbance, or a pre-menarcheal 'menstrual' cycle. The results of our study also suggest that an endocrinological lunar cycle, similar to the menstrual cycle, exists in pre-menarcheal girls. Further observations of a much greater number of female MZ twins and a much larger quantity of endocrinological evidence will be required to confirm this hypothesis, however.

\section{REFERENCES}

1. Brown KGC, Darby CW, Ng SH (1991): Cyclical disturbance of diabetic control in girls before the menarche. Arch Dis Childhood 66:1279-1281.

2. Fischbein S (1977): Onset of puberty in MZ and DZ twins. Acta Genet Med Gemellol 26:152-158.

3. Petri E (1935): Untersuchugen zur Erbbedingtheit der Menarche. $Z$ Morphol Anthropol 33:43-48.

4. Tisserand-Perrier M (1961): Étude comparative de certain processus de croissance chez les jumeaux. J Genet Hum 2:87-102.

Correspondence: Prof. Izumi Nakamura, Japan Women's College of Physical Education, Kita-Karasuyama, Setagaya-ku, Tokyo 157, Japan 